\title{
Ionic liquids. Green solvents for the future*
}

\author{
Martyn J. Earle and Kenneth R. Seddon \\ The QUILL Centre, Stranmillis Road, The Queen's University of Belfast, Northern \\ Ireland, BT9 5AG, UK
}

Abstract: Ionic liquids, being composed entirely of ions, were once mainly of interest to electrochemists. Recently, however, it has become apparent that, inter alia, their lack of measurable vapor pressure characterizes them as green solvents, and that a wide range of chemical reactions (reviewed here) can be performed in them.

\section{INTRODUCTION}

To date, most chemical reactions have been carried out in molecular solvents. For two millennia, most of our understanding of chemistry has been based upon the behavior of molecules in the solution phase in molecular solvents. Recently, however, a new class of solvent has emerged-ionic liquids. These solvents are often fluid at room temperature, and consist entirely of ionic species. They have many fascinating properties which make them of fundamental interest to all chemists, since both the thermodynamics and kinetics of reactions carried out in ionic liquids are different to those in conventional molecular solvents, then the chemistry is different and unpredictable at our current state of knowledge. However, in addition to the scope for exciting new discoveries with which they tease us, ionic liquids have no measurable vapor pressure, and hence can emit no volatile organic compounds (VOCs). They have attracted, quite justifiably, enormous attention as media for green synthesis, and this review attempts to capture, in a few pages, the scope and promise of the work published to date.

As they are made up of at least two components which can be varied (the anion and cation), the solvents can be designed with a particular end use in mind, or to possess a particular set of properties. Hence, the term "designer solvents" has come into common use [1]. At first, the prospect of carrying out chemical reactions in ionic liquids may seem daunting to a chemist who has not worked with them before, but it turns out that carrying reactions out in ionic liquids can be exceptionally easy.

The field of ionic liquids has been reviewed by several authors, including Welton [2], Holbrey [3], and Seddon [4]. The first room-temperature ionic liquid $\left[\mathrm{EtNH}_{3}\right]\left[\mathrm{NO}_{3}\right]\left(\mathrm{m} . \mathrm{pt.} 12{ }^{\circ} \mathrm{C}\right)$ was discovered in 1914 [5], but interest did not develop until the discovery of binary ionic liquids made from mixtures of aluminum(III) chloride and $N$-alkylpyridinium [6] or 1,3-dialkylimidazolium chloride [7]. In general, ionic liquids consist of a salt where one or both the ions are large, and the cation has a low degree of symmetry. These factors tend to reduce the lattice energy of the crystalline form of the salt, and hence lower the melting point [8]. Ionic liquids come in two main categories, namely simple salts (made of a single anion and cation) and binary ionic liquids (salts where an equilibrium is involved). For example, $\left[\mathrm{EtNH}_{3}\right]\left[\mathrm{NO}_{3}\right]$ is a simple salt whereas mixtures of aluminum(III) chloride and 1,3-dialkylimidazolium chlorides (a binary ionic liquid system) contain several different ionic species, and their melting point and properties depend upon the mole fractions of the aluminum(III) chloride and 1,3-dialkylimidazolium chloride present. Examples of ionic liquids consisting of a simple salt are given in Fig. 1, and these

\footnotetext{
*Pure Appl. Chem. Vol. 72, No. 7, 2000. A special topic issue on green chemistry. As this article was being completed, an excellent account of some of the latest unpublished results on the green applications of ionic liquids appeared in Chemical and Engineering News (pp. 37-50, 15 ${ }^{\text {th }}$ May, 2000), in which Michael Freemantle reported at length on the proceedings of the first international meeting on ionic liquids, a NATO Advanced Research Workshop entitled "Green Industrial Applications of Ionic Liquids", held in Crete 12-16 April 2000 (the full proceedings will be published by Kluwer next year).
} 

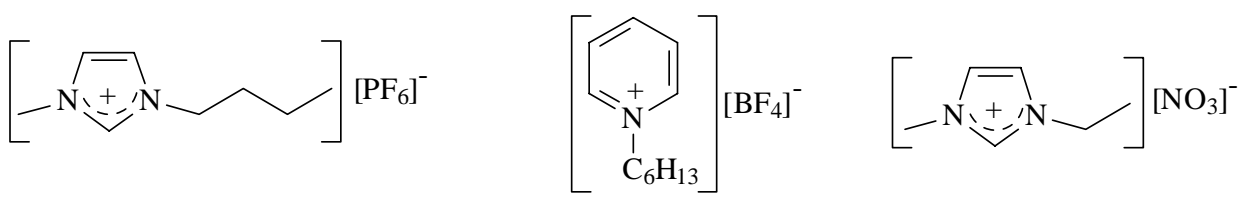

Fig. 1 Examples of simple room-temperature ionic liquids.

show simple melting behavior. For the binary systems, the melting point depends upon composition,* and this complex behavior has been studied extensively for the archetypal system, [emim]Cl- $\mathrm{AlCl}_{3}$ ([emim $]^{+}=1$-ethyl-3-methylimidazolium) [9].

Ionic liquids have been described as designer solvents [1], and this means that their properties can be adjusted to suit the requirements of a particular process. Properties such as melting point, viscosity, density, and hydrophobicity can be varied by simple changes to the structure of the ions. For example, the melting points of 1-alkyl-3-methylimidazolium tetrafluoroborates [10] and hexafluorophosphates [11] are a function of the length of the 1-alkyl group, and form liquid crystalline phases for alkyl chain lengths over 12 carbon atoms. Another important property that changes with structure is the miscibility of water in these ionic liquids. For example, 1-alkyl-3-methylimidazolium tetrafluoroborate salts are miscible with water at $25^{\circ} \mathrm{C}$ where the alkyl chain length is less than 6 , but at or above 6 carbon atoms, they form a separate phase when mixed with water. This behavior can be of substantial benefit when carrying out solvent extractions or product separations, as the relative solubilities of the ionic and extraction phase can be adjusted to make the separation as easy as possible.

\section{REACTIONS IN CHLOROALUMINATE(III) IONIC LIQUIDS}

The chemical behavior of Franklin acidic chloroaluminate(III) ionic liquids (where $X\left(\mathrm{AlCl}_{3}\right)>0.50$ ) is that of a powerful Lewis acid. As might be expected, it promotes reactions that are conventionally promoted by aluminum(III) chloride, without suffering the disadvantage of the low solubility of aluminum(III) chloride in many solvents. Indeed, chloroaluminate(III) ionic liquids are exceptionally powerful solvents, being able to dissolve kerogen [12], $\mathrm{C}_{60}$ and many polymers [13]. The preparation of these ionic liquids is straightforward. Simply by mixing the appropriate organic halide salt with aluminum(III) chloride results in the two solids melting together to form the ionic liquid. However, this synthesis must be performed in an inert atmosphere.

A classical reaction promoted by Lewis acids is the Friedel-Crafts reaction, which was found to work efficiently in chloroaluminate(III) ionic liquids [14]. A number of commercially important fragrance molecules have been synthesized by Friedel-Crafts acylation reactions in these ionic liquids [15]. Traseolide ${ }^{\circledR}$ (5-acetyl-1,1,2,6-tetramethyl-3-isopropylindane) and Tonalid ${ }^{\circledR}$ (6-acetyl-1,1,2,4,4,7hexamethyltetralin) have been made in high yield in the ionic liquid [emim] $\mathrm{Cl}_{-} \mathrm{AlCl}_{3}(X=0.67)$ (Fig. 2). In the acylation of naphthalene, the ionic liquid gives the highest known selectivity for the 1-position [15].

Cracking and isomerization reactions occur readily in acidic chloroaluminate(III) ionic liquids. A remarkable example of this is the reaction of polyethylene, which is converted to a mixture of gaseous alkanes with the formula $\left(\mathrm{C}_{n} \mathrm{H}_{2 n+2}\right.$, where $\left.n=3-5\right)$ and cyclic alkanes with a hydrogen to carbon ratio of less than two (Fig. 3) [16]. The distribution of the products obtained from this reaction depends upon the reaction temperature and differs from other polyethylene recycling reactions in that aromatics and

*The composition of a tetrachloroaluminate(III) ionic liquid is best described by the apparent mole fraction of $\mathrm{AlCl}_{3}\left\{X\left(\mathrm{AlCl}_{3}\right)\right\}$ present. Ionic liquids with $X\left(\mathrm{AlCl}_{3}\right)<0.5$ contain an excess of $\mathrm{Cl}^{-}$ions over $\left[\mathrm{Al}_{2} \mathrm{Cl}_{7}\right]^{-}$ions, and are called "basic"; those with $X\left(\mathrm{AlCl}_{3}\right)>0.5$ contain an excess of $\left[\mathrm{Al}_{2} \mathrm{Cl}_{7}\right]^{-}$ions over $\mathrm{Cl}^{-}$, and are called "acidic"; melts with $X\left(\mathrm{AlCl}_{3}\right)=0.5$ are called 'neutral'. 


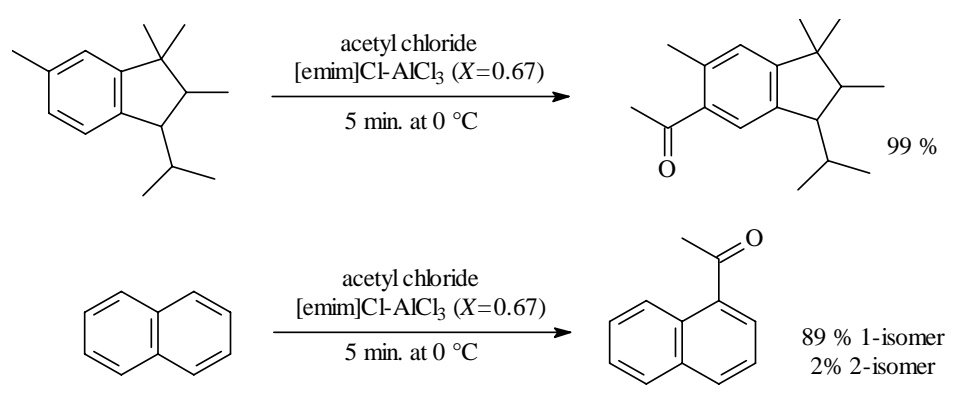

Fig. 2 The acetylation of 1,1,2,6-tetramethyl-3-isopropylindane (upper) and naphthalene (lower) in [emim]Cl$\mathrm{AlCl}_{3}(X=0.67)[15]$.
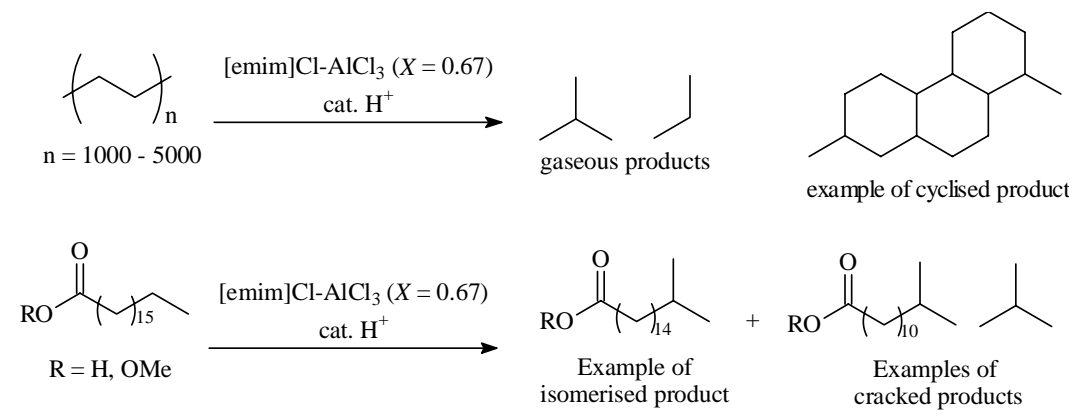

Fig. 3 Isomerization and cracking reactions of alkanes and alkyl chains in chloroaluminate(III) ionic liquids $[16,18,19]$.

alkenes are not formed in significant concentrations [16]. Another significant difference is that this ionic liquid reaction occurs at temperatures as low as $90{ }^{\circ} \mathrm{C}$, whereas conventional catalytic reactions require much higher temperatures, typically $300-1000{ }^{\circ} \mathrm{C}$ [17]. A similar reaction occurs with fatty acids such as stearic acid or methyl stearate, which undergo isomerization, cracking, and dimerization reactions. This has been used to convert solid stearic acid into the more valuable liquid, isostearic acid [18]. The isomerization and dimerization of oleic acid and methyl oleate has also been found to occur in chloroaluminate(III) ionic liquids [19].

The dimerization and oligomerization of olefins in the presence of homogeneous nickel(II) catalysts has been studied extensively in chloroaluminate(III) and alkylchloroaluminate(III) ionic liquids $[20,21]$. Few catalysts are known that catalyze the linear dimerization and oligomerization of $\mathrm{C}_{4}$-olefins. Linear $\mathrm{C}_{8}$-olefin dimers are highly desirable intermediates for the production of $\mathrm{C}_{9}$-plasticizers, exhibiting better thermal properties than those produced from highly branched $\mathrm{C}_{8}$-olefin dimer feedstock. This has been developed commercially in the IFP Difasol process [1]. The products of these reactions are insoluble in the ionic liquid and can be separated by decantation, leaving the ionic liquid and catalyst behind, whence the catalyst and solvent can be reused.

Polycyclic aromatic hydrocarbons dissolve in chloroaluminate(III) ionic liquids to form highly colored paramagnetic solutions [22]. The addition of a reducing agent, such as an electropositive metal, and a proton source results in the selective hydrogenation of the aromatic compound. For example, pyrene and anthracene can be reduced to perhydropyrene and perhydroanthracene at ambient temperatures and pressures; only the thermodynamically most stable isomer of the product is obtained [23]. This contrasts with catalytic hydrogenation reactions, which require high temperatures and pressures, and an expensive platinum oxide catalyst and give rise to an isomeric mixture of products [24]. By

(C) 2000 IUPAC, Pure and Applied Chemistry 72, 1391-1398 


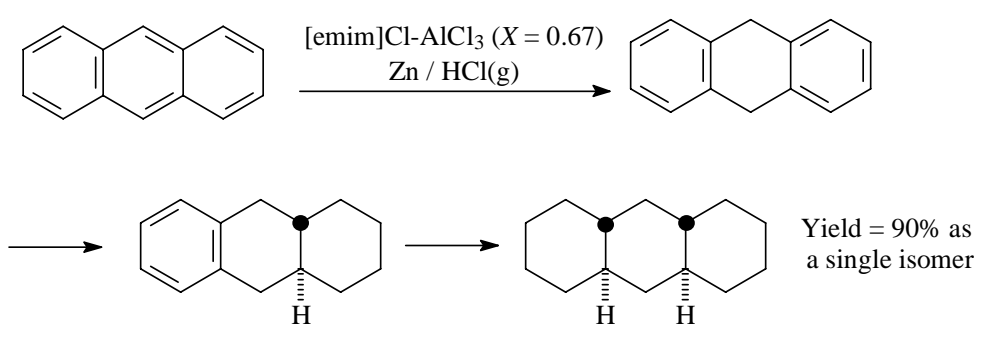

Fig. 4 The sequence in the reduction of anthracene to perhydroanthracene [23].

careful monitoring of the reduction in the ionic liquid, a number of intermediate products can be isolated, and the sequence of the chemical reduction process can be determined (Fig. 4).

It is also possible to carry out catalytic hydrogenation reactions of cyclohexene using Wilkinson's catalyst, $\left[\mathrm{RhCl}\left(\mathrm{PPh}_{3}\right)_{3}\right]$, in basic chloroaluminate(III) ionic liquids [25], but neutral ionic liquids are preferred for this type of reaction, for ease of handling and lower moisture sensitivity.

\section{NEUTRAL IONIC LIQUIDS}

Chloroaluminate(III) ionic liquids are excellent catalysts and solvents in many processes, but suffer from several disadvantages, such as their moisture sensitivity and the difficulty of separation of products containing heteroatoms from the ionic liquid, whilst leaving the ionic liquid intact. In order to develop chemistry in ionic liquids, and increase the robustness of processes, water-stable ionic liquids have become increasingly important. In particular, a number of ionic liquids have been found to be hydrophobic, but yet readily dissolve many organic molecules, with the exception of alkanes and alkylated aromatic compounds (such as toluene). An example of this is the ionic liquid $[\mathrm{bmim}]\left[\mathrm{PF}_{6}\right]\left([\mathrm{bmim}]^{+}=1\right.$-butyl-3methylimidazolium) [26], which forms triphasic mixtures with alkanes and water. This multiphasic behavior has important implications for clean synthesis, and is analogous to the use of fluorous phases in some chemical processes [27]. For example, transition-metal catalysts can be exclusively dissolved in the ionic liquid, thus allowing products and by-products to be separated from the ionic liquid by solvent extraction with either water or an organic solvent. This is of key importance when using precious metal catalysts or catalysts with expensive ligands, enabling both the ionic liquid and catalyst to be recycled and reused. Alternatively, some volatile products can be separated from the ionic liquid and catalyst by distillation, as the ionic liquid has effectively no vapor pressure and therefore cannot be lost. There also exists the possibility of extraction with supercritical solvents. A recent example is the use of supercritical carbon dioxide to extract naphthalene from $\left[b_{m i m}\right]\left[\mathrm{PF}_{6}\right][28]$.

Special conditions are not usually required when carrying out reactions in neutral ionic liquids. For example, there is often no need to exclude water, or to carry out the reaction under an inert atmosphere. This, combined with the ability to design the ionic liquid to allow for easy separation of the product, makes reactions in ionic liquids extremely straightforward to carry out.

\section{REACTIONS IN NEUTRAL IONIC LIQUIDS}

Neutral ionic liquids have been extensively studied as solvents for hydrogenation reactions. A key advantage of ionic liquids is that homogeneous transition-metal catalysts can be used and the products of the reaction can be easily separated from the ionic liquid and catalyst [2]. Examples of this include the hydrogenation of cyclohexene [29], and the complete hydrogenation of benzene rings [30]. Recently, asymmetric hydrogenation reactions have appeared. An example is in the synthesis of (S)-Naproxen (Fig. 5) in the ionic liquid [bmim] $\left[\mathrm{BF}_{4}\right][31]$. 
<smiles>C=C(C(=O)O)c1ccc2cc(OC)ccc2c1</smiles><smiles>COc1ccc2cc(C(C)C(=O)O)ccc2c1</smiles>

Fig. 5 The synthesis of (S)-Naproxen in $[\mathrm{bmim}]\left[\mathrm{BF}_{4}\right][31]$.

Neutral ionic liquids have also been found to be excellent solvents for the Diels-Alder reaction [32,33], giving significant rate enhancement over molecular solvents, including water, which is normally considered to enhance the rate of this chemical reaction [34]. The selectivities in this reaction can be improved from 4:1 to 20:1 by the addition of a mild Lewis acid such as zinc(II) iodide (Fig. 6) [32]. One of the key benefits of this is that the ionic liquid and catalyst can be recycled and reused after solvent extraction or direct distillation of the product from the ionic liquid. The reaction has also been carried out in chloroaluminate(III) ionic liquids, but the moisture sensitivity of these systems is a major disadvantage [35].

A particularly useful reaction is the palladium-catalyzed coupling of aryl halides with alkenesthe Heck reaction. It has been found that many palladium complexes dissolve in ionic liquids [36] and allow the products and by-products of the Heck reaction to be extracted with either water or alkane solvents (Fig. 7) [37]. This allows the expensive catalyst to be easily recycled as it remains in the ionic phase. This differs from conventional Heck reactions, in which the catalyst is usually lost at the end of the reaction, and noxious dipolar aprotic solvents are used. An alternate Heck reaction uses aromatic anhydrides as a source of the aryl group (Fig. 7). This has the advantage that the by-product of the reaction is benzoic acid (which can readily be converted back to the anhydride) and that halide containing waste is not formed. Other reactions that have been found to proceed under similar conditions, include palladium(II) acetate catalyzed allylation and amination reactions in [bmim] $\left[\mathrm{BF}_{4}\right]$ [38]. An example is the alkylation of dimethyl malonate by 3-acetoxy-1,3-diphenylprop-1-ene.

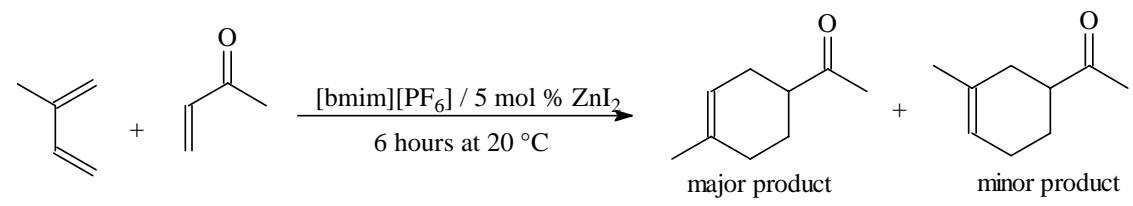

Fig. 6 The zinc(II) iodide catalyzed reaction of isoprene with but-3-en-2-one in the ionic liquid [bmim] $\left[\mathrm{PF}_{6}\right]$ [32].

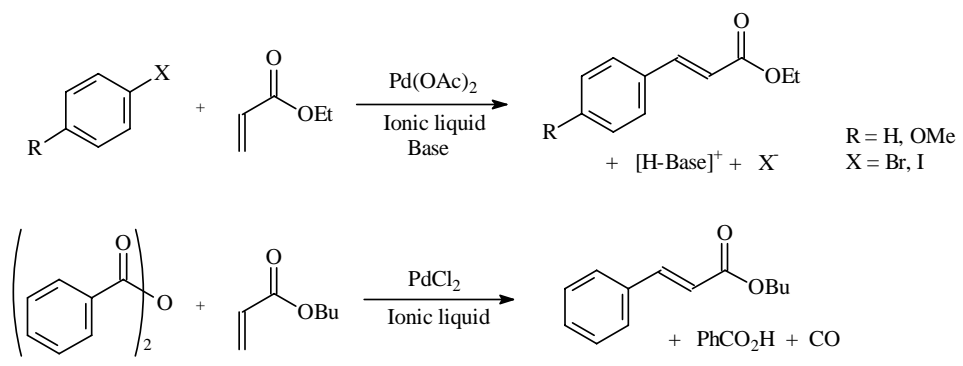

Fig. 7 The Heck reactions of aryl halides and anhydrides in ionic liquids [37].

(C) 2000 IUPAC, Pure and Applied Chemistry 72, 1391-1398 


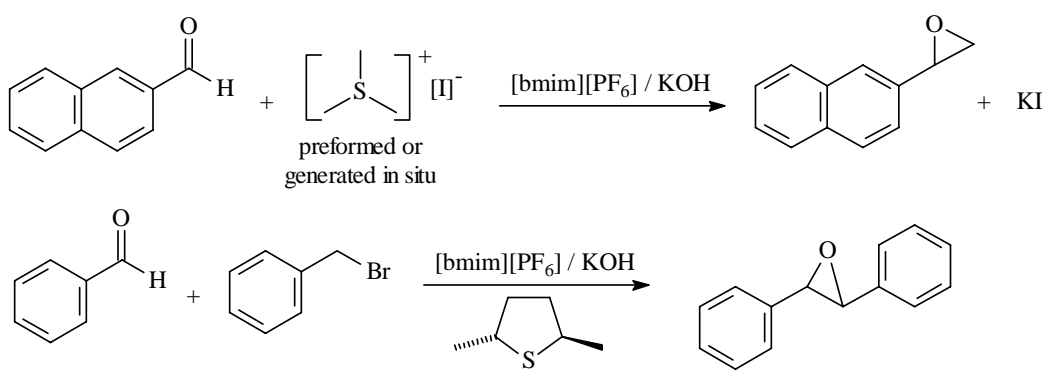

Fig. 8 Methylene insertion reactions in $[\mathrm{bmim}]\left[\mathrm{PF}_{6}\right][40]$.

One of the most common reactions in organic synthesis is the nucleophilic displacement reaction. Indole and 2-naphthol undergo alkylation on the nitrogen and oxygen atoms, respectively, when treated with a haloalkane and base (usually $\mathrm{NaOH}$ or $\mathrm{KOH}$ ) in $[\mathrm{bmim}]\left[\mathrm{PF}_{6}\right]$ [39]. These reactions occur with similar rates to those carried out in dipolar aprotic solvents such as DMF or DMSO. The advantage of the ionic liquid process is that the products of the reaction can be extracted into an organic solvent such as toluene, leaving the ionic liquid behind. The by-product (sodium or potassium halide) of the reaction can be extracted with water, and the ionic liquid recycled. This contrasts with the use of dipolar aprotic solvents, where they are difficult to remove from the product.

Methylene insertion reactions have been found to work effectively in ionic liquids such as $[\mathrm{bmim}]\left[\mathrm{PF}_{6}\right]$ or $[\mathrm{bmim}]\left[\mathrm{BF}_{4}\right]$. Alkyl halides react with sulfides to form sulfonium ylides. The reactions work equally well with preformed sulfonium salts or with dialkyl sulfides and methyl iodide in the reaction vessel. These can be used to transfer a methylene group to aldehydes or ketones (Fig. 8). By use of a chiral sulfide such as $2 \mathrm{R}, 5 \mathrm{R}$-tetrahydrothiophene, it is possible to carry out asymmetric methylene insertion reactions in good enantiomeric excess. The product (stilbene oxide) can be extracted from the ionic liquid with toluene, and the by-product (potassium halide) extracted with water. After drying, the ionic liquid and chiral catalyst can be reused for further reactions [40].

The addition of organometallic reagents to carbonyl compounds is an important reaction in organic chemistry, with the Grignard reaction being prototypic. Gordon and McClusky [41] have reported the formation of homoallylic alcohols, from the addition of allyl stannanes to aldehydes in the ionic liquids $[\mathrm{bmim}]\left[\mathrm{BF}_{4}\right]$ and $[\mathrm{bmim}]\left[\mathrm{PF}_{6}\right]$. It was found that the ionic liquid could be recycled and reused over several reaction cycles.

A surprising use of ionic liquids is in bio-transformations. Room-temperature ionic liquids, such as $[\mathrm{bmim}]\left[\mathrm{PF}_{6}\right]$, have been used as direct replacements for conventional organic solvents in multiphase bioprocess operations. Examples include the liquid-liquid extraction of the antibiotic erythromycin and two-phase biotransformation processes [42].

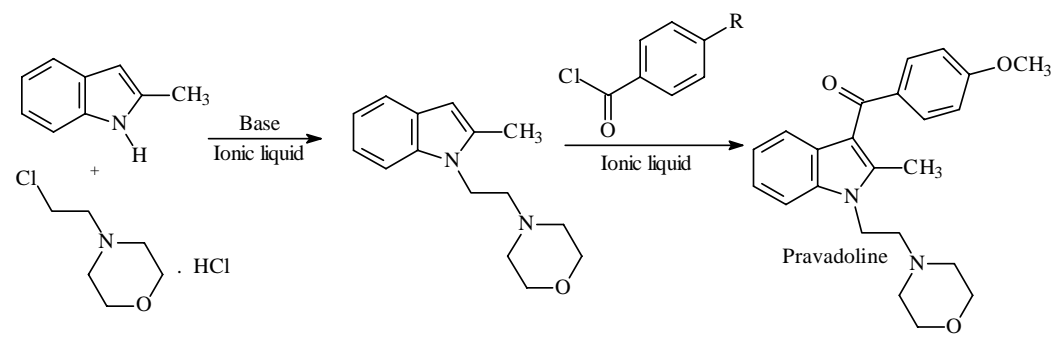

Fig. 9 The complete synthesis of pravadoline in [bmim] $\left[\mathrm{PF}_{6}\right]$ [43].

(C) 2000 IUPAC, Pure and Applied Chemistry 72, 1391-1398 


\section{TOTAL SYNTHESIS IN IONIC LIQUIDS}

Pravadoline was selected as a demonstration of the complete synthesis of a pharmaceutical in an ionic liquid, as it combines a Friedel-Crafts reaction and a nucleophilic displacement reaction (Fig. 9) [43]. The alkylation of 2-methylindole with 1-(N-morpholino)-2-chloroethane occurs readily in [bmim] $\left[\mathrm{PF}_{6}\right]$ at room temperature in $95 \%$ yield, using potassium hydroxide as the base. The yield can be improved to $99 \%$ using the ionic liquid 1-butyl-2,3-dimethylimidazolium hexafluorophosphate ([bdmim $\left.]\left[\mathrm{PF}_{6}\right]\right)$. The Friedel-Crafts acylation of the product from the nucleophilic displacement reaction can be performed in chloroaluminate(III) ionic liquids at $0{ }^{\circ} \mathrm{C}$, but the best results occur in $[\mathrm{bmim}]\left[\mathrm{PF}_{6}\right]$ at $150{ }^{\circ} \mathrm{C}$. It should be noted that no catalyst is required in this Friedel-Crafts reaction, and thus the amount of waste formed is reduced. When $\mathrm{KOH}$ is used as the base in both steps of the reaction, the only waste from the whole synthesis is aqueous potassium chloride, which compares favourably with the original synthesis that produces large amounts of acidic aluminum waste and uses a dipolar aprotic solvent [44]. Moreover, the ionic liquid process does not require strictly anhydrous conditions or an inert atmosphere to carry out the reaction. This makes the whole reaction sequence easier, cheaper, and less time consuming to perform.

\section{CONCLUSIONS}

The range of reactions in ionic liquids gives a flavour of what can be achieved in these neoteric solvents. Because the properties and behavior of the ionic liquid can be adjusted to suit an individual reaction type, they can truly be described as designer solvents. We have shown that, by choosing the correct ionic liquid, high product yields can be obtained, and a reduced amount of waste can be produced in a given reaction. Often the ionic liquid can be recycled, and this leads to a reduction of the costs of the processes. It must be emphasized that reactions in ionic liquids are not difficult to perform and usually require no special apparatus or methodologies. The reactions are often quicker and easier to carry out than in conventional organic solvents.

\section{ACKNOWLEDGMENTS}

We would like to thank the QUILL Centre (M. J. E.) for financial support, and the EPSRC and the Royal Academy of Engineering for the award of a Clean Technology Fellowship (K. R. S.).

\section{REFERENCES}

1. M. Freemantle. Chem. Eng. News 76, (30 March) 32-37 (1998).

2. T. Welton. Chem. Rev. 99, 2071-2083 (1999).

3. J. Holbrey and K. R. Seddon. Clean Prod. Proc. 1, 223-236 (1999).

4. K. R. Seddon. J. Chem. Tech. Biotech. 68, 351-356 (1997).

$5 \quad$ P. Walden. Bull. Acad. Imper. Sci. (St. Petersburg) 1800 (1914).

6. H. L. Chum, V. R. Koch, L. L. Miller, R. A. Osteryoung. J. Am. Chem. Soc. 97, 3264-3267 (1975).

7. J. S. Wilkes, J. A. Levisky, R. A. Wilson, C. L. Hussey. Inorg. Chem. 21, 1236-1264 (1982).

8. K. R. Seddon. In Molten Salt Forum: Proceedings of 5th International Conference on Molten Salt Chemistry and Technology, Vol. 5-6, H. Wendt (Ed.), pp. 53-62 (1998).

9. C. L. Hussey, T. B. Scheffler, J. S. Wilkes, A. A. Fannin, Jr. J. Electrochem. Soc. 133, 1389-1391 (1986).

10. J. D. Holbrey and K. R. Seddon. J. Chem. Soc., Dalton Trans. 2133-2139 (1999).

11. C. M. Gordon, J. D. Holbrey, A. R. Kennedy, K. R. Seddon. J. Mater. Chem. 8, 2627-2636 (1998).

12. L. Dutta, A. Fleet, Y. Patell, K. R. Seddon, unpublished results.

13. M. J. Earle and K. R. Seddon, unpublished results.

(C) 2000 IUPAC, Pure and Applied Chemistry 72, 1391-1398 
14. J. A. Boon, J. A. Levisky, J. L. Pflug, J. S. Wilkes. J. Org. Chem. 51, 480-483 (1986).

15. C. J. Adams, M. J. Earle, G. Roberts, K. R. Seddon. Chem. Commun. 2097-2098 (1998).

16. C. J. Adams, M. J. Earle, K. R. Seddon. Green Chem. 2, 21-23 (2000).

17. R. W. J. Westerhout, J. Waanders, J. A. M. Kuipers, W. P. van Swaaij. Ind. Eng. Chem. Res. 37, 2293-2300 (1998).

18. C. J. Adams, M. J. Earle, J. Hamill, C. M. Lok, G. Roberts, K. R. Seddon. World Patent WO 98 07680, (1998).

19. C. J. Adams, M. J. Earle, J. Hamill, C. M. Lok, G. Roberts, K. R. Seddon. World Patent WO 98 07679 (1998).

20. B. Ellis, W. Keim, P. Wasserscheid. Chem. Commun. 337-338 (1999).

21. Y. Chauvin, H. Olivier, C. N. Wyrvalski, L. C. Simon, R. F. de Souza. J. Catal. 275-278 (1997).

22. P. Tarakeshwar, J. Y. Lee, K. S. Kim. J. Phys. Chem. A 102, 2253-2255 (1998).

23. C. J. Adams, M. J. Earle, K. R. Seddon. Chem. Commun. 1043-1044 (1999).

24. D. K. Dalling and D. M. Grant. J. Am. Chem. Soc. 96, 1827-1834 (1974).

25. P. A. Z. Suarez, J. E. L. Dullius, S. Einloft, R. F. de Souza, J. Dupont. Polyhedron 15, 2127-2129 (1996).

26. J. D. Huddleston, H. D. Willauer, R. P. Swatloski, A. E. Visser, R. D. Rogers. Chem. Commun. 1765-1766 (1998).

27. L. P. Barthel-Rosa and J. A. Gladysz. Coord. Chem. Rev. 192, 587-605 (1999).

28. L. A. Blanchard, D. Hancu, E. J. Beckman, J. F. Brennecke. Nature 399, $28-29$ (1999).

29. P. A. Z. Suarez, J. E. L. Dullius, S. Einloft, R. F. de Souza, J. Dupont. Inorg. Chim. Acta. 225, $207-$ 209 (1997).

30. P. J. Dyson, D. J. Ellis, D. G. Parker, T. Welton. Chem. Commun. 25-26 (1999).

31. A. L. Monteiro, F. K. Zinn, R. F. de Souza, J. Dupont. Tetrahedron Asymmetry 8, 177-179 (1997).

32. M. J. Earle, P. B. McCormac, K. R. Seddon. Green Chem. 1, 23-25 (1999).

33. T. Fisher, A. Sethi, T. Welton, J. Woolf. Tetrahedron Lett. 40, 793-795 (1999).

34. D. C. Rideout and R. J. Breslow. J. Am. Chem. Soc. 102, 7816-7822 (1980).

35. C. W. Lee. Tetrahedron Lett. 40, 2461-2462 (1999).

36. W. A. Herrmann and V. P. W. Bohn. J. Organomet. Chem. 572, 141-142 (1999).

37. A. J. Carmichael, M. J. Earle, J. D. Holbrey, P. B. McCormac, K. R. Seddon. Org. Lett. 1, $997-$ 1000 (1999).

38. W. Chen, L. Xu, C. Chatterton, J. Xiao. Chem. Commun. 1247-1248 (1999).

39. M. J. Earle, P. B. McCormac, K. R. Seddon. Chem. Commun. 2245-2246 (1998).

40. M. J. Earle. P. B. McCormac, K. R. Seddon. To be published.

41. C. M. Gordon and A. McClusky. Chem. Commun. 1431-1432 (1999).

42. S. G. Cull, J. D. Holbrey, V. Vargas-Mora, K. R. Seddon, G. T. Lye. Biotechnol. Bioeng. 69, $227-$ 233 (2000).

43. M. J. Earle, P. B. McCormac, K. R. Seddon. Green Chemistry, in press.

44. M. R. Bell, T. E. Dambra, V. Kumar, M. A. Eissenstat, J. L. Herrmann, J. R. Wetzel, D. Rosi, R. E. Philion, S. J. Daum, D. J. Hlasta, R. K. Kullnig, J. H. Ackerman, D. R. Haubrich, D. A. Luttinger, E. R. Baizman, M. S. Miller, S. J. Ward. J. Med. Chem. 34, 1099-1110 (1991). 